\title{
Relato de experiência sobre a reflexão da conduta passiva em ambiente escolar
}

\author{
Experience report on the reflection of the passive conduct in the school \\ environment
}

\begin{abstract}
Relato de experiencia sobre la reflección de la conducta pasiva en ambiente escolar
\end{abstract}

\author{
João Paulino Perini ${ }^{1}$ \\ Ma. Sabrina Alves de Souza ${ }^{2}$ \\ Eslen Delanogare ${ }^{3}$ \\ Douglas Flores de Oliveira ${ }^{4}$
}

\begin{abstract}
Resumo
Este artigo trata-se do relato de experiência sobre um trabalho de estágio desenvolvido no curso de Psicologia de uma universidade do noroeste do estado do Rio Grande do Sul, o qual consiste em abordagem com professores e alunos de uma escola pública de ensino fundamental. O objetivo foi proporcionar discussões para a qualificação das relações do professor com seus pares e com a profissão. Participaram das reuniões cerca de 15 professores de maio à julho de 2016. Paralelamente, no mesmo período, 20 alunos do $9^{\circ}$ ano participaram de encontros de atualização dos significados das atuações institucionais em ambiente escolar. A partir da ótica psicológica de Martinez, Lück, entre outros, foram elaboradas práticas que corroboraram a movimentação institucional para a elaboração de estratégias de participação ativa dos membros da gestão, coordenação e professores na rotina escolar. Os encontros e reuniões tiveram a participação da gestão, que ao final do estágio tomou postura ativa na condução participativa dos problemas institucionais.
\end{abstract}

Palavras-chave: escola, experiência, gestão, passividade, psicologia.

\section{Resumen}

\footnotetext{
${ }^{1}$ Universidade Regional Integrada do Alto Uruguai e das Missões - URI; Santo Ângelo, Rio Grande do Sul; Brasil.joao_perini@hotmail.com

${ }^{2}$ Mestra em Educação; Universidade Regional Integrada do Alto Uruguai e das Missões - URI; Santo Ângelo, Rio Grande do Sul; Brasil. sabrina@ urisan.tche.br

${ }^{3}$ Universidade Regional Integrada do Alto Uruguai e das Missões - URI; Santo Ângelo, Rio Grande do Sul; Brasil. dalenogare22@hotmail.com

${ }^{4}$ Universidade Regional Integrada do Alto Uruguai e das Missões - URI; Santo Ângelo, Rio Grande do Sul; Brasil. umparadoxo@gmail.com
} 
Este artículo se trata de un relato de experiencia sobre un trabajo de estagio desarrollado en el curso de psicología en una universidad en el noroeste de Rio Grande do Sul, el cual consiste en abordaje con profesores y alumnos de una escuela primária pública. El objetivo fue proporcionar discusiones para la calificación de las relaciones del profesor con sus pares y con la profesión. Participaron de las reuniones cerca de 15 profesores de mayo a júlio de 2016. Paralelamente, en el mismo período, 20 alumnos de $9^{\circ}$ año participaron de encuentros de actualización de los significados de las actuaciones institucionales en ambiente escolar. A partir de la óptica psicológica de Martinez, Lück, entre otros, fueron elaboradas prácticas que corroboraron la movimentación institucional para la elaboración de estratégias de participación activa de los miembros de la gestión, coordinación y profesores en la rutina escolar. Los encuentros y reuniones tuvieron la participación de la gestión, que al final del estágio tomo postura activa en la conducción participativa de los problemas institucionales.

Palabras clave: escuela, experiencia, gestión, pasividad.

\begin{abstract}
This summary comes from the experience report about an internship work in the course of Psychology at a university in the northwest of Rio Grande do Sul state, which is to approach with teachers and students from a public elementary school. The objective was to provide discussion for the qualification of the teacher's relationships with their peers and the profession. Attended the meetings about 15 teachers from May to July 2016. In parallel, in the same period, 20 students from 9th grade participated in meetings to update the meanings of institutional roles in the school environment. From the psychological optical of Martinez and Lück, among others, practices were developed that supported the institutional drive for the development of active participation strategies of members of the management, coordination and teachers in the school routine. The meetings had the participation of the management, which at the end of the stage took active role in participatory conduct of institutional problems.
\end{abstract}

Kewords: experience, management, passivity, psychology, school

\title{
1. Introdução
}

As escolas são instituições que tem como principal função o ensino e a aprendizagem. Por se tratar de um ambiente que está sob condições de muitas variantes e inúmeras relações, sofre pelas mais diversas ingerências.

O espaço escolar proporciona ao aluno situações nem sempre favoráveis para a externalização de suas ansiedades. Condições estas que, por vezes, favorecem a construção de um ambiente hostil que impossibilita questionamentos específicos sobre o domínio do contexto escolar, pessoal e inter-relacional daqueles que transitam no espaço educativo.

Profissionais da área da Psicologia desenvolvem projetos com a finalidade de proporcionar aos atores institucionais espaço para reflexão de suas condutas intersubjetivas. Acerca da atuação do psicólogo na escola, este deve exercer um papel preventivo, contemplando alguns aspectos importantes, como o processo ensino/aprendizagem, a mediação das relações dentro da escola, envolvendo professores, família e funcionários que fazem parte desta instituição, e o desenvolvimento da personalidade destes alunos, para que no decorrer da vida estudantil os mesmos se expandam, conhecendo a si mesmos, e assim podendo se relacionar com a sociedade. Sobre esse papel do psicólogo em ambiente escolar, Martinez (2010) entende que 
A partir de um sensível processo de diagnóstico e análise das necessidades institucionais, o psicólogo pode sugerir, delinear e coordenar estratégias de intervenção direcionadas a potencializar o trabalho em equipe, mudar representações cristalizadas e inadequadas sobre o processo educativo, desenvolver habilidades comunicativas, mediar conflitos, incentivar a criatividade e a inovação, melhorar a qualidade de vida no trabalho e outras tantas ações, como contribuição significativa para o aprimoramento do funcionamento organizacional.(p.48)

O aluno tem consigo experiências já adquiridas ao chegar à escola. A quantidade e a qualidade da experiência ainda não são conhecidas. O psicólogo escolar, num trabalho direto com os alunos, pode colaborar para desvendar e reconhecer o que está presente nas relações e, além disso, em um trabalho grupal conceber relações mais saudáveis entre todos os integrantes do processo de ensino-aprendizagem, favorecendo que as inter-relações sejam as mais proveitosas possíveis e que delas se consiga verificar aprendizagens consistentes e melhores resultados. Todavia é importante compreender que o psicólogo se torna o profissional mais indicado a suscitar e instigar tal empreitada no cenário escolar, sem, no entanto, prescindir das contribuições de todos os setores deste e, especialmente, da prática dos profissionais que formam, com ele, a equipe pedagógica e a escola. (CORREIA, LIMA e ARAÚJO, 2001, p.560).

No âmbito escolar podem existir variados contextos e até situações que dificultem os objetivos das instituições que o compõem. Os professores e os alunos, como parte da instituição "escola", também devem receber atenção aos seus problemas, que muitas vezes afetam não somente sua atuação na escola, mas, em conjunto, suas vidas particulares. Assim como podem levar suas frustrações pessoais para a escola, suas relações com os outros sujeitos que participam de seu cotidiano escolar, os conflitos e dificuldades que surgem delas, podem interferir em contexto ainda mais amplo.

A proposta de trabalhar desenvolvimento interpessoal na escola tem o objetivo de preparar esse indivíduo tanto para o período em que vive no espaço pedagógico, quanto para quando ele sair desse território de convivências, possibilitando-o apresentar habilidades ao fazer seus contatos e se estabelecer de forma satisfatória em suas atividades, sejam profissionais, familiares, ou qualquer outra que envolva sua vida. (LEITE, 1997). O autor também afirma ser necessário existir dentro da escola um momento que propicie a discussão das relações.

O início do estágio apresentou-se pouco produtivo. As considerações assertivas de todo processo se desenvolveram conforme as resistências institucionais foram se dissolvendo e transformando-se em confiança, ocasionando o aumento de interesse da gestão sobre as práticas desenvolvidas através do estágio. Tal percepção ocasionou a identificação da real 
demanda da escola, caracterizada pela passividade da gestão. Essa demanda foi recebida e analisada pelo estagiário, com a finalidade de elaboração de novos projetos que pudessem suprir as necessidades apresentadas pela instituição.

O educador, por estar em contato direto com o educando e ser o principal responsável pela construção do conhecimento, pode tanto promover a aprendizagem como também dificultá-la. Na maioria das vezes os professores desconhecem os efeitos malignos de sua atuação ineficiente e acham que a culpa é sempre do aluno. (CARNEIRO, 2003)

Desta forma, devido ao professor não conseguir enxergar a ruptura em sua forma de ensino ou outros aspectos, o psicólogo pode colaborar criando um espaço para que ele possa refletir suas práticas, incentivar seu desenvolvimento acerca dos instrumentos utilizados em sala de aula, encorajando os educadores a construírem dispositivos que ativem a criatividade para a resolução de problemas na escola.

Por esse motivo deve ser observado, em conjunto, o "lado do professor", de suas dificuldades particulares, das situações a que se expõe, entre elas a desvalorização de sua profissão, o desinteresse por parte dos alunos, a baixa remuneração que recebe e o acúmulo de alunos em sala de aula, o que denota a depreciação de tais condições por parte do Estado. Todos esses fatores contribuem para a desmotivação deste profissional e corroboram com a intensificação desse estigma.

Frequentemente temos ouvido várias reclamações, por parte dos professores, das situações por eles vivenciadas e que os tornam desmotivados com a profissão e com o trabalho que realizam. Essas reclamações tornam a profissão "professor" desvalorizada e têm diminuído sensivelmente o status da profissão. (CERQUEIRA et al, p.1)

Acreditando que os anseios de professores e alunos devem ser conhecidos e trabalhados de forma adequada e contextualizados na perspectiva social, o estagiário de Psicologia desenvolveu encontros paralelos com professores e alunos. Em função da compreensão das dificuldades diárias das pessoas que compõem o cenário de prática pedagógica, tornou-se necessário a realização do trabalho com professores e alunos paralela e simultaneamente, a fim de que fossem criados espaços de discussão e reflexão que possibilitassem a ressignificação das respectivas funções e a construção conjunta de estratégias para a alteração das relações intersubjetivas.

O presente artigo é consequência da intervenção produzida pelo Estágio em Instituições Sociais - Ênfase AI de uma universidade do noroeste do estado, e apresenta os resultados da experiência prática do estagiário em âmbito escolar e das questões 
teórico/práticas referentes ao trabalho com professores e alunos de uma escola do município do noroeste do estado do Rio Grande do Sul. O objetivo é relatar a experiência de condução de dois projetos simultâneos de manejo dos aspectos inter-relacionais de alunos e professores, desenvolvidos com metodologia participativa, na qual se procurou repensar a identidade social e cultural do contexto escolar. Ao final do período de execução dos projetos, foram propostas a devolução dos aspectos observados e a elaboração de novas intervenções em parceria direta com a gestão e coordenação da escola.

\section{Estratégias metodológicas}

Como estratégias metodológicas foram utilizadas atividades que estabeleceram recortes institucionais do cotidiano do contexto em questão. Um deles foi a realização de encontros semanais em sala de aula com os alunos do $9^{\circ}$ ano. Paralelamente, outro recorte foram as reuniões com os professores que aconteceram esporadicamente conforme a disponibilização do calendário escolar.

O trabalho com os alunos foi de caráter reflexivo, direcionando atenção para a produção de vieses externos frente às escolhas desses estudantes. Para que isso fosse analisado, propuseram-se encontros semanais de 45 minutos de duração cada um. Durante os encontros foi entregue algum material impresso ou realizado algum relato verbal para que os alunos discorressem sobre o que pensavam a respeito do assunto, com o intuito de correlacionar o conteúdo exposto com o significado do papel de aluno.

Os encontros tiveram o objetivo de produzir discussões sobre o papel que o aluno e os agentes institucionais representam e sobre as expectativas esperadas pelos pais dos estudantes. Durante os encontros, foi disponibilizado o espaço para livre manifestação de opiniões e pensamentos do tema sugerido, desde a função da escola na vida dos estudantes à atuação dos mesmos na manutenção da rotina escolar.

No trabalho proposto com os professores foram realizados encontros de grupo, através de atividades como seminários, onde foram discutidos, abertamente, os assuntos solicitados pelos participantes, e assim, possibilitando a problematização de suas questões. A coleta de informações sobre suas práticas foi realizada por meio da tomada de respostas de entrevistas semiestruturadas, que segundo Manzini (2004) "além de coletar as informações básicas, serve como um meio para o pesquisador se organizar para o processo de interação com o informante". As entrevistas foram citadas em todo o contexto da elaboração do relatório final do estágio. Essas sessões de entrevistas potencializaram o foco do professor frente suas expectativas e conhecimentos técnicos. Também foram realizadas dinâmicas que puderam 
auxiliar na comunicação entre os membros do grupo, fazendo com que eles conseguissem se integrar de maneira eficiente.

\section{Compreensão dinâmica dos contextos}

Depois de enviada uma breve descrição do projeto proposto, a direção da escola formalizou o pedido para a realização da intervenção. A estrutura organizacional da instituição escola é composta por uma diretora, duas coordenadoras - uma responde pelo turno da manhã e a outra, pelo da tarde - além de 25 professores(as). O funcionamento é desde a educação infantil até o nono ano do ensino fundamental, englobando cerca de 300 alunos.

Toda estrutura física da escola é considerada pequena, já que secretaria e a sala dos professores também servem para outas funções, como depósito de jogos, sala da coordenação e direção e locação dos armários dos professores. Essa distribuição dos espaços administrativos com outras funções interfere na complexa dinâmica na rotina escolar.

Dessa forma, percebeu-se que os espaços físicos e humanos da escola estavam demasiadamente confusos, disponíveis ao jogo de interesses individuais e carentes de uma logística que privilegiasse as práticas coletivas. Por não possuir um responsável nominado, a biblioteca, por exemplo, ficava sob os cuidados da diretora em conjunto com a coordenação, sendo utilizada, inclusive para reuniões e encontros esporádicos com os pais dos alunos. Já os espaços que possuíam porta com fechadura geralmente se encontravam trancados. A livre circulação dos alunos e funcionários era relativa e dependia da autorização da diretora ou da coordenação. Desde as primeiras visitas à escola, observou-se uma hierarquia centralizada na figura da diretora.

Tais aspectos relacionados à estrutura física da escola e que levavam às condutas individualistas na instituição foram compreendidos pela maioria dos atores institucionais. No período de aplicação do projeto, a descaracterização da representatividade política e de gestão era evidente já nas primeiras observações apontadas na coleta de dados.

\section{Reflexionamento teórico/prático}

No decorrer da segunda metade do estágio, na maior parte do tempo a escola foi favorável à intervenção. A gestão, muitas vezes, se apresentou perdida em suas decisões administrativas e do fazer pedagógico. Percebeu-se a dificuldade de criar iniciativas para a promoção de novas práticas, demonstrando certa resistência, aspectos observados diante da falta de iniciativa política da instituição. 
Houve, sim, um esforço por parte do grupo para articular soluções para estas dificuldades e, a instituição identificou a necessidade de algum tipo de mudança, mas sempre alertados de que para isso ser efetivado, seria fundamental retomar as bases estruturais das condutas técnicas que sempre a mantiveram. Importante ressaltar que os projetos não tiveram a intenção de remover as estruturas alicerçadas da cultura daquela unidade escolar, mas, sim, questionar as condutas que enrijeceram a atuação daqueles que ocupam esse espaço: estudantes, professores e gestores.

Em princípio, o modelo da estrutura escolar analisada se constitui em uma dinâmica e clara divisão entre professores e alunos. Na instituição observada, se estabelece essa constituição de disputa que, inicialmente, faz parte do jogo “ensinar/aprender”. Essas práticas são constatadas em outros contextos, como salienta Gasparian (1997).

O professor, através do ritual pedagógico (cópias, correções, exercícios, etc.), procura pôr em prática o conteúdo a ser transmitido e é nesse confronto entre o que se deve ensinar e o que se deve aprender que surgem novas formas de aproximação entre professor e aluno, criando um todo complexo de relações, onde entra em jogo a história individual de cada um, bem como o contexto social. (p. 14)

Nessa discussão, o objetivo era de que a escola, por meio de seus agentes, pudesse identificar, analisar e contribuir para possíveis soluções dos problemas apontados. No entanto, a percepção limitada de suas estruturas técnicas se tornara impeditivo ao sucesso do desempenho analítico. Isso porque, na escola observada, a maioria dos professores desconhece a fundamental "metodologia de ensino". Quando questionados sobre suas metodologias de ensino, a maior parte deles respondeu de forma inconclusiva, sem clareza e até mesmo demonstrando desconhecimento sobre o conteúdo da pergunta. Portanto, viu-se o questionamento: Se para professor falta o aporte técnico básico, como ele poderá elaborar estratégias de ensino/aprendizagem novas, atualizadas e interessantes?

Essa variável corrobora diretamente uma das principais queixas dos professores: a desvalorização da profissão. E quando questionados sobre esse aspecto, responderam, em sua maioria, que essa desvalorização vem "das pessoas que não reconhecem a importância do professor". Ora, entende-se que, se o sujeito não possui o aparato técnico mínimo que o qualifique e o identifique como tal, como ele pode exigir que seja valorizado? Constata-se que sua valorização junto com a qualificação técnica estão esquecidos em alguma sala de aula da graduação cerca de 15 anos atrás.

No entanto, a formação continuada poderia desenvolver o ensino de professores o que é dificilmente produzido em ambiente escolar. Segundo Dugnani e Souza (2011) como 
formação continuada, não são admitidos grupos de estudos, mas somente cursos formalizados que tenham controle de frequência, notas atribuídas e certificação ao seu final. Com a qualificação técnica, os professores, juntamente com a coordenação pedagógica poderiam desenvolver estratégias para a valorização da classe docente. Todavia, como elucidado por Placco, Almeida e Souza (2011), deve haver no Brasil a urgência de formações que contemplem as necessidades de desenvolvimento profissional dos orientadores. Parece-nos que os grupos de estudo, sobretudo aqueles voltados à reflexão, poderiam auxiliar o Orientador Pedagógico na construção de seu papel de formador na escola e no planejamento de suas ações. Entretanto, os orientadores, na maioria das vezes, acabam participando dos mesmos cursos destinados aos professores, tanto os oferecidos pela Secretaria de Educação, quanto àqueles realizados fora da rede.

Essa condição estruturante, da dinâmica da instituição em questão, está ligada a outra variável. A partir das estimativas dos próprios professores e equipe diretiva, em média, $40 \%$ dos pais "não" participam da vida escolar dos filhos. Esse fenômeno, segundo os professores, é uma das causas dos problemas encontrados na prática diária da atividade letiva. Contudo, quando questionados sobre quais as estratégias utilizadas para a comunicação com as famílias, eles se mostram apáticos, passivos e desesperançados.

Observou-se que a desqualificação técnica interfere na elaboração de estratégias de intervenção com as famílias, como indica Gasparian (1997), quando esse explica que a escola é funcional desde que conte com forte aliança com a comunidade, o corpo docente e administrativo, que trabalham para colaboração e diálogo. A flexibilidade dessas estruturas facilita a utilização de várias técnicas e métodos adequados. Por isso, sugere-se que o sistema de papéis sociais dos atores institucionais possuam fronteiras bem delimitadas e que ao mesmo tempo permitam trocas de cunho colaborativo.

A psicologia escolar pautada por essa visão, de que o problema estava, principalmente e em alguns casos, somente no aluno, foi percebendo que outras variáveis e situações poderiam estar envolvidas no processo das dificuldades apresentadas pelos estudantes em sala, e que a responsabilidade pelo fracasso não era apenas deles. (ANDRADA, 2005). Entretanto, o aluno como centro do problema na escola, já foi deixado para trás, tornando-se agora, parte de um todo, que afeta os que integram a escola, juntamente com ele.

Hoje sabemos que é impossível ouvir um aluno e não levar em conta a relação desses com os próprios pais, professores e com a escola. (LIMA, 2007). Considerando essa premissa, devemos entender a importância de que o trabalho seja realizado com os professores e todos 
os outros indivíduos que participam da comunidade escolar. Dessa forma, faz-se necessário encontrar estratégias para alcançar esses profissionais.

Dentre tantas queixas, a passividade foi umas das principais reclamações dos professores em relação ao comportamento das turmas do final do Ensino Fundamental. Tal atitude está atrelada a muitas variáveis. Porém, observaram-se, nos encontros, as nuances que perpetuam esse estigma:

- A imposição da escola como único agente de ensino;

- A configuração de uma prática disciplinadora institucionalizada;

- O professor como o único detentor do conhecimento;

- Paradoxalmente, o reforço da posição passiva do aluno confrontada pela exigência de posição ativa do aluno.

O psicólogo passou a visar o aluno como um ser que não deve desenvolver-se apenas cognitivamente, pois ele também é um ser social e precisa construir habilidades para relacionar-se com o meio em que vive. Pensando o papel do psicólogo neste contexto, Martínez (2010) afirma que:

Contribuir no sentido de mudanças reais nas formas pelas quais os indivíduos pensam, sentem e atuam, são requeridas estratégias educativas sistêmicas e permanentes, em correspondência tanto com a complexidade da subjetividade humana quanto com a complexidade de seus processos de mudança. Por essas razões, o trabalho do psicólogo, nessa direção, tem particular relevância. (p. 46)

A observação direta dos alunos do $9^{\circ}$ ano identificou, de fato, essa passividade frente às adversidades sociais da instituição. No entanto, novamente, percebeu-se que a falta de manejo dos professores com os alunos demonstra a acomodação dos papeis sociais dos mesmos. A uniformidade de um rito comum parecia ecoar em toda a instituição: "Ficaremos onde estamos porque aqui é seguro". De forma evidente, esse modo de agir incentivava a "crença" dos professores e do grupo diretivo para a "não aprendizagem" que, segundo as estimativas dos professores, é de $40 \%$. Expectativa que aparece repetidamente em outros aspectos, mas que não serão descritos nesse artigo por não possuir dados suficientes.

Outro aspecto interessante nessa análise é que o professor não apenas ensina com seus conteúdos pré-estipulados. O aluno é suscetível a aprender o que o professor transmite através de suas atitudes, inclusive. "Por isso o professor que não vivenciou uma verdadeira apropriação do saber não poderá acompanhar o aluno na construção do seu próprio conhecimento, já que ele próprio, professor, não o percorreu." (GASPARIAN, 1997, p. 69). 
Os encontros com os professores por muitas vezes soaram como Gomes e Meireles (2007) descrevem, quando o psicólogo pode ser visto pelos professores como um “fiscalizador”, inserido na escola para observá-los coordenado pela direção. Apesar de esta não ser a realidade do trabalho do psicólogo escolar, este é um pensamento que pode surgir para os professores, e que vai inibi-los, de alguma forma, de se interessar em participar de atividades com este profissional.

$\mathrm{Na}$ prática, apesar de terem sido realizados poucos encontros, foi possível perceber a importância de os professores terem um espaço para manifestar suas divergências e dificuldades. Segundo uma pesquisa realizada por Cerqueira (2006), investigando os problemas na profissão dos professores, apareceu que:

Os sete problemas mais citados pelos professores foram: desvalorização da profissão professor, grande número de alunos em sala de aula, salário baixo, desinteresse dos alunos, carga horária baixa da disciplina, desmotivação geral dos professores e baixo rendimento escolar dos alunos. $(\mathrm{p}, 1)$.

Nas falas apresentadas pelos professores, o principal problema que enfrentam na profissão está relacionado à baixa remuneração, já que consideram o próprio trabalho como algo de fundamental importância, já que atuam na formação da aprendizagem de crianças e adolescentes. Com isso, demonstraram o sentimento que possuem de sua profissão ser desvalorizada.

Os aspectos estruturais que mantem a instituição resultam em um sistema complexo. Esse sistema sofre influências estatais que corroboram a estagnação dos processos educativos e revelam as nuances das emoções dos agentes que exercem suas práticas, enunciadas em trabalho, como autodepreciação. As implicações dessas diretrizes estatais atravessam as práticas pessoais e são, aqui, entendidas como um sintoma da gestão que estava passiva em seu contexto organizacional. A partir das observações produzidas no contexto institucional, entendemos que o "aperfeiçoamento" da gestão atual possibilita que se alterem as determinações instituídas, como aponta Lück (2009) quando fala sobre gestão de pessoas em escolas:

Fundamentalmente, a vitalidade da escola, na promoção de educação de qualidade, centra-se na competência das pessoas que a compõem e realizam o seu fazer pedagógico e em sua determinação em promover ensino de qualidade voltado para a formação e aprendizagem dos alunos. Não são o seu prédio, seus bens materiais e equipamentos, sua tecnologia, seus planos de ação em si que garantem a qualidade de ensino. Estes elementos são subsídios e instrumentos de apoio que, não sendo movidos e empregados adequadamente por pessoas, pouco contribuem para a efetividade da educação, por melhores que sejam. (p.82) 
Todavia, é necessário que as pessoas que compõem a estrutura administrativa e institucional da escola entendam a urgência da dimensão de suas problemáticas, e que, a partir da tomada de consciência das estruturas, seja possível pensar e desenvolver estratégias para a solução dos problemas apresentados.

Nos dias que antecederam o final da intervenção do estagiário, a instituição, representada pela gestão e coordenação, esteve mais à frente de suas decisões, produzindo reflexionamentos acerca de novas perspectivas, passando de conduta passiva para práticas ativas como: delegação de tarefas, discussão de estratégias de comunicação para com a comunidade, elaboração de estruturas que facilitem a comunicação interna, restituição de acordos para delimitação das fronteiras dos espaços físicos e de papeis sociais, estruturação de pedidos de apoio à Secretaria Municipal de Educação, viabilização de apoio pedagógico específico para os professores.

\section{Considerações finais}

No período inicial do estágio compreendeu-se a baixa participação política dos agentes institucionais. Muitos foram os discursos de reprovação das tentativas de implementação de novas práticas. As resistências foram, de forma geral, tanto do departamento diretivo quanto dos professores e alunos. Alguns problemas foram detectados durante todo o processo, como aponta Correia (2007) ao afirmar que as dificuldades que se colocam à colaboração e à reflexão passam, grosso modo, pela escassez de tempo e pela organização do modo trabalho dos departamentos onde a ação das lideranças assume especial importância.

No entanto, não foi proposta nenhuma alteração forçada na rotina da escola. O acordo era de que o apoio do estagiário de Psicologia estivesse presente em momentos dificeis vividos pela instituição. Houve um esforço para ouvir as lamentações de ambos os grupos, mas sempre com referência à importância de uma postura ativa frente às adversidades das práticas realizadas por todos na escola.

Outro aspecto importante foi a disposição dos professores e da equipe diretiva em relação às duas maneiras de agir frente à presença do estagiário no local. Percebe-se que o papel do estagiário na escola variava de acordo com o turno e até das pessoas que circulavam na escola nesses horários. Dependendo das configurações das diferentes pessoas que circulavam pelo espaço, mudavam as condutas e, em alguns momentos, o afastavam da 
prática; assim como em outros momentos, ficava claro como o papel do estagiário era vinculado aos processos e julgamentos de decisões da organização escolar.

É pertinente colocar que tal experiência aponta que a atuação de um profissional de Psicologia pode proporcionar maior liberdade de exposição e reflexão de ideias por parte dos alunos dentro do espaço, além de beneficiar o debate sobre outros temas de interesse dos educandos. De acordo com Kupfer (1997), além de abrir espaço para a fala, o psicólogo coloca-se também em posição de escuta ativa. Assim, as pessoas têm o seu momento para falar e ao mesmo tempo tem alguém para ouvi-los, o que pode construir um ambiente de confiança na relação entre os integrantes do grupo. "O objetivo do trabalho do psicólogo na escola é o de abrir um espaço para a circulação de discursos, naquelas instituições em que a ausência dessa circulação estiver comprometendo a realização dos objetivos institucionais". (KUPFER, 1997, p. 57).

A compreensão do papel do psicólogo na escola é discutida há mais de três décadas. Segundo Andaló (1984), normalmente, para o psicólogo é destinado o papel de apenas tratar o "aluno-problema", de forma que ele possa voltar "desproblematizado" para a institucionalização da sala de aula. A oportunidade de realizar um trabalho com professores mostra que ainda há conceitos equivocados sobre a atuação do psicólogo na escola. Eles parecem pensar que o psicólogo continua com uma prática exclusivamente clínica, focada no aluno e à serviço de diagnósticos e laudos.

Entretanto o que mais apareceu na rotina escolar foram as queixas, as reclamações que melindram a conduta e o desempenho de toda a instituição. Sugere-se que os agentes institucionais sejam influenciados por uma postura ativa nas adversidades, que possibilitem a racionalização de seus sentimentos, a compreensão reativa de suas frustrações e, assim, possam construir o ambiente propício para pensar suas contribuições da dinâmica escolar.

No presente relato, entendemos que o trabalho realizado serviu mais para coletar dados e embasar uma possível melhora na atuação da gestão, prevista para a segunda fase de intervenções do projeto. Vale ressaltar que, quando os momentos finais da intervenção chegaram, vieram junto algumas disrrupturas com o modelo vigente. As percepções sobre as alterações da mudança institucional estavam direcionadas às relaçoes interpessoais. A gestão passou a um posicionamento firme em relação às responsabilidades dos papeis institucionais.

Após a alteração da conduta passiva da gestão para posição ativa, vislumbramos que a mudança começou a se tornar efetiva, corroborando o que Correia (2007) elucida sobre a emergência de um novo estilo de liderança que seja capaz de fomentar a confiança, o envolvimento, a participação, o questionamento e a reflexão conjunta é crucial para o 
desenvolvimento da colaboração e da reflexão entre os professores tendo como referência o projeto educativo da escola.

Em seguida a execução dos projetos, percebeu-se que os maiores beneficiados com a intervenção foram a direção e a coordenação, visto que estavam prontos para se posicionar para a imediata solução de problemas. Entendeu-se que essa alteração de paradigma estava latente na instituição e isso facilitou todo o processo de intervenção para a identificação, análise e aplicação de estratégias de mudança do cenário institucional. Essas estratégias dependem do que Correia (2007) entende como a criação de uma estrutura de trabalho flexível, intra e interdepartamental, semelhante a um mosaico fluído, podendo constituir uma oportunidade de os professores se envolverem em equipes que os ajudem na reflexão sobre, na e pela escola. A dinâmica desta nova estrutura de trabalho está dependente da existência de um interesse comum partilhado por todos, o que requer uma constante negociação de significados, objetivos e processos.

Já a experiência do projeto com os alunos se mostrou importante para a coleta, intervenção e posteriormente análise dos dados para o reconhecimento das falhas do processo ensino/aprendizagem num panorama mais amplo. Os dados coletados possibilitaram, ainda, perceber a discrepância entre teoria e prática nas rotinas escolares e no processo ensino/aprendizagem. As diferentes posições dos alunos e sua identificação com a instituição trouxeram características implícitas e dados que contribuíram para ressignificar o modelo instituído.

Foi possível produzir, ainda, a devolução das informações contidas no relatório do estágio, expostas de forma didática e sutil, destacando cada ponto observado durante o projeto. Entende-se que o artigo é um pequeno esboço para a construção de estratégias de intervenção posterior com professores, alunos e gestão.

Ao final do estágio observou-se a alteração da perspectiva passiva da gestão para a contemplação de atitudes ativas diante das problemáticas do cotidiano escolar. Com a devolução dos dados para a instituição, o estagiário esteve disponível para elaborar conjuntamente estratégias de ação e discutir uma possível nova intervenção no segundo semestre de 2016. Porém, tais dados também propiciaram a perspectiva de que é possível implementar ações determinantes de alteração dos paradigmas institucionais vigentes na unidade escolar em questão.

\section{Referências}


ANDALÓ, Carmem. O papel do psicólogo escolar. Psicologia: Ciência e Profissão. v.4, n.1, p.43-46, Brasília, 1984.

ANDRADA, Edla. Focos de intervenção em psicologia escolar. Psicologia escolar e educacional. v.9, n.1, p.163-165. 2005.

CARNEIRO, Karina. Atividades em grupo na formação continuada de professores do ensino superior. $31^{\circ}$ Congresso Brasileiro de Educação em Engenharia. Rio de Janeiro, 2003.

CERQUEIRA, Ana. et al. Os professores e os problemas enfrentados da profissão. $25^{\circ}$ Reunião Anual da Sociedade Brasileira de Química. Minas Gerais, 2007.

CORREIA, Mônica. LIMA, Anna. ARAUJO, Claudia. As Contribuições da Psicologia Cognitiva e a Atuação do Psicólogo no Contexto Escolar. Psicologia Reflexão e Critica, v.14, n.3, p.553-561. 2001.

CORREIA, Ana. Contributos do projecto educativo para o trabalho colaborativo e reflexivo entre os professores: estudo de um caso. Repositório Aberto. v.2 Lisboa, 2007.

DUGNANI, Lilian Aparecida Cruz; SOUZA, Vera Lúcia Trevisan de. Os sentidos do trabalho para o orientador pedagógico: contribuições da Psicologia Escolar. Psicologia da Educação, São Paulo, n. 33, p. 29-47, 2011.

GASPARIAN, Maria. Psicopedagogia institucional sistêmica: contribuição do modelo relacional sistêmico para a psicopedagogia institucional. São Paulo: Lemos Editorial, 1997.

GOMES, Sheyla. MEIRELES, Algeless. A concepção dos professores a respeito da atuação do Psicólogo nas escolas privadas/ensino fundamental. Psicologia para América Latina, n.11, p.0-0, Teresina. 2007.

KUPFER, M. O que toca à/a psicologia escolar. São Paulo, 1997.

MACHADO, A. e SOUZA, M.(Orgs.). Psicologia escolar: em busca de novos rumos, São Paulo: Casa do Psicólogo, 1997.

LEITE, D. M. (1997). Educação e relações interpessoais. In: M. H. S. Patto (Org.), Introdução à psicologia escolar (pp. 301-327). São Paulo: Casa do Psicólogo.

MARTINEZ, A. M. (2010). O que pode fazer o psicólogo na escola? Em Aberto, Brasília, março, v. 23, n.83, p. 39-56.

LÜCK, Heloísa. Dimensões de gestão escolar e suas competências. Curitiba: Editora Positivo, 2009.

MANZINI, Eduardo. Entrevista semi-estruturada: Análise de objetivos e de roteiros. II Seminário internacional de pesquisa e estudos qualitativos. Bauru, 2004.

PLACCO, V. M; ALMEIDA, L. R., \& SOUZA, V. T. O coordenador pedagógico e a formação de professores: intenções, tensões e contradições. Acessado em 15 julho de 2016, http://www.fvc.org.br/pdf/apresentacao-coordenadores-qualitativo.pdf 